\section{ROMER'S ADVERSARIA.}

Ole Römer's Adversaria, med Understöttelse af Carlsbergfondet udgione af det $\mathrm{Kgl}$. Danske Videnskabernes Selskab. By Thyra Eibe and Kirstine Meyer. Pp. v+27r. (Köbenhavn: Bianco Lunos Bogtrykkeri, I9Io.)

A MONG astronomers Ole Römer (1644-1710) occuA pies a peculiar position. $\mathrm{He}$ was held in high repute among contemporary men of science, as may be seen from the fact that Newton and he were the first astronomers to be enrolled among the eight foreign associates of the Paris Academy of Sciences, and were elected on the same day. To posterity he is known as the discoverer of the gradual propagation of light, and as the man who introduced the use of (if he did not invent) the transit instrument and the transit circle. And yet his published writings only fill a few pages, and the observations he made with instruments far superior in design to those of his time, were not printed, and nearly all of them perished not long after his death. There is, therefore, every reason to welcome the publication of his common-place book, which has been brought out just two hundred years after his death.

Like every other book of its kind, the present book of Adversaria deals in a scrappy way with a great variety of subjects, and it shows what chiefly occupied Römer's mind, especially during the last ten years of his life. We see him as a practical astronomer, as a physicist, and as a man who had for many years served his country well by reorganising the system of weights and measures, getting the Gregorian calendar introduced, and preparing a uniform system of land taxation. But though these various occupations, which gradually came to fill most of his time to the great loss of science, are now and then alluded to in the present volume, they do not fill many pages in it. It looks as if Römer was in the habit of taking refuge in his commonplace book when he wanted to refresh his mind after his hard worl as Burgomaster and Chief of Police of Copenhagen. To give a full account of the contents of his notes is not possible in a limited space: we can only give the reader some idea of the kind of subjects dealt with. An important section on thermometers, dating from 1702, has already been described in Nature, (vol. 1xxxii., p. 296). Römer appears to have been the first to construct thermometers with two fixed points, marking the temperatures of melting snow and of boiling water, and he was the inventor of the scale known as Fahrenheit's.

Turning to astronomical matters, we find Romer to have been a follower of Descartes in his views on the construction of the universe, though his own discovery about light did not exactly harmonise with Cartesian ideas. He inquires at what distance a planet or satellite would have to be from the central body according to the third law of Kepler in order that its period of revolution may equal the period of rotation of the central body. In the case of a planet he finds the distance equal to 37 semidiameters of the sun, in the case of a satellite of the earth $6 \frac{1}{2}$, and for a satellite of Jupiter 2 semidiameters of the respec- tive planet. This, he thinks, may be made to agree with the vortex theory by assuming that radiation from the central body impedes the rotation of the ether, and this radiation, being naturally much more powerful from the sun, causes its influence to be felt at a much greater distance than that at which the radiation of a planet is perceptible. He shows himself interested in solar phenomena by calculating the apparent position of the sun's axis, and of the path of sun-spots for every $7^{\frac{1}{2}}{ }^{\circ}$ of longitude of the sun, having first determined the inclination of the sun's equator and the place of the node with fair accuracy from his own and La Hire's observations. It will be remembered that the sun's equator was in those days often used as a fundamental plane or Via Regia of the solar system. He calculates the transit of Mercury of May, 1707, from Kepler's elements and observations by Hevelius of the transit of May, 166r. He calculates the solar eclipse of September I3, I708, for Copenhagen, and Holum in Iceland, and gives rules for the prediction and graphic representation of an eclipse. The transit instrument in the prime vertical, of which he had introduced the use, is employed for the determination of the vernal equinox of 1702 , and he examines the consequences of errors of observation in the transit, and shows how to determine the error of collimation by reversing the instrument.

The above examples, which could easily be multiplied, will show that the two ladies who have edited this book have done good work by bringing it to light. There is a useful index and an excellent table of contents, and every care seems to have been taken to produce an accurate edition of the old manuscript. The few Danish words or sentences occurring here and there might have been translated in foot-notes for the convenience of readers not acquainted with that language.

J. L. E. D.

\section{GALL-FLIES AND OTHERS.}

Das Tierreich. Eine Zusammenstellung und Kennzeichnung der rezenten Tierformen. Edited by F. E. Schulze. 24 Lieferung. Hymenoptera. Cynipidæ. By Prof. K. W. von Dalla Torre and Prof. J. J. Kieffer. Pp. xxxv +89 r. (Berlin : R. Friedlander and Son, I9Io.) Price 56 marks.

THIS work forms a worthy volume of the series 1 of zoological works published under the general title of "Das Tierreich," by Messrs. R. Friedlander and Son, of Berlin. It is an extension of the two volumes by Dr. Kieffer in André's "Species des Hyménoptères d'Europe et de 1'Algérie." Dealing as it does with the Cynipidæ of the whole world, and containing descriptions of all the known genera and species, the book is indispensable to students of the Cynipidæ. Theodore Hartig was the pioneer of the scientific study of the group. He placed the classification on a proper basis, and was the first to point out the threefold habits of the species-gall-makers, inquilines, and parasites. After him came Giraud, Schenk, and, above all, G. L. Mayr, who made the identification of the galls easy by the publication of beautifully illustrated works on the species of Central Europe, as well as a monograph on the guest-flies (Synergi).

$$
\text { NO. } 2 \text { I57, VOI. 86] }
$$

